Article

\title{
Increasing Iron and Reducing Phosphorus Grades of Magnetic-Roasted High-Phosphorus Oolitic Iron Ore by Low-Intensity Magnetic Separation-Reverse Flotation
}

\author{
Junhui Xiao ${ }^{1,2,3,4, *}$ and Lingli Zhou ${ }^{2}$ \\ 1 Key Laboratory of Ministry of Education for Solid Waste Treatment and Resource Recycle, \\ Southwest University of Science and Technology, Miangyang 621010, China \\ 2 State Key Laboratory of Refractories and Metallurgy, Wuhan University of Science and Technology, \\ Wuhan 030192, China; fan.blanca@hotmail.com \\ 3 Key Laboratory of Radioactive and Rare Scattered Minerals, Ministry of Land and Resources, \\ Shaoguan 512026, China \\ 4 Sichuan Engineering Laboratory of Non-Metallic Mineral Powder Modification and High-Value Utilization, \\ Southwest University of Science and Technology, Mianyang 621010, China \\ * Correspondence: xiaojunhui33@163.com; Tel.: +86-13990190544
}

Received: 22 May 2019; Accepted: 18 June 2019; Published: 21 June 2019

\begin{abstract}
High-phosphorus oolitic iron ore, treated by suspended flash magnetic roasting, contained $42.73 \%$ iron (mainly present as magnetite) and $0.93 \%$ phosphorus (present as collophane). Low-intensity magnetic separation (LIMS) was combined with reverse flotation to increase the iron and reduce the phosphorus contents of the roasted product. The results showed that an optimized iron ore concentrate with an iron grade of $67.54 \%$, phosphorus content of $0.11 \%$, and iron recovery of $78.99 \%$ were obtained under LIMS conditions that employed a grind of $95 \%-0.038 \mathrm{~mm}$ and a magnetic field of $0.10 \mathrm{~T}$. Optimized rougher reverse-flotation conditions used a pulp pH of 9 and dosages of toluenesulfonamide, starch, and pine alcohol oil of $800 \mathrm{~g} / \mathrm{t}, 1000 \mathrm{~g} / \mathrm{t}$, and $40 \mathrm{~g} / \mathrm{t}$, respectively; optimized scavenging conditions used a pulp pH of 9 and dosages of toluenesulfonamide, starch, and pine alcohol oil of $400 \mathrm{~g} / \mathrm{t}, 500 \mathrm{~g} / \mathrm{t}$, and $20 \mathrm{~g} / \mathrm{t}$, respectively. Study of the mechanism of phosphorus reduction showed that the toluenesulfonamide could be adsorbed on the surface of quartz after the action of starch, but adsorption was significantly weakened. The starch inhibitor negatively affected adsorption on quartz, but positively influenced adsorption of phosphorus minerals.
\end{abstract}

Keywords: suspended magnetic roast; low-intensity magnetic separation; reverse flotation; phosphorus mineral flotation reagent; iron increase; phosphorous reduction

\section{Introduction}

Suspended flash magnetic roasting is a new technology for the treatment of refractory iron ore. Raw materials, such as refractory iron ores with low grade and low-intensity magnetization (e.g., siderite, limonite, hematite, and goethite) or iron-containing tailings, can be processed by drying and grinding without need of pelletization. The raw material ore powder is exchanged with hot exhaust gas discharged from the magnetic roaster after a multi-stage cyclone preheater and enters the suspended magnetic roasting reaction furnace, which is characterized by its high temperature and weakly reducing atmosphere [1-3]. The fine dry mineral powder is contacted in a suspended state with $\mathrm{CO}$ and reacts instantaneously. The low-intensity magnetic iron oxide is then converted to ferromagnetic oxide [4]. The ore powder after magnetic roasting is subjected to a multi-stage 
low-intensity magnetic separation (LIMS) process to obtain high-grade iron concentrate products. Materials such as coal, natural gas, coal gas, and combustible exhaust gas can be used as fuel for this process [5]. Suspended flash magnetic roasting is characterized by its high magnetization velocity, high production efficiency, high magnetic susceptibility, no need for secondary high-temperature oxidation, high iron recovery, and sufficient utilization of iron ores resource [6,7]. LIMS is often adopted to recover iron in this process, but deleterious elements, such as phosphorus, sulfur, and silicon, must still be removed by methods including reverse flotation and acid leaching to obtain qualified iron concentrate products.

The available reserves of high-phosphorus oolitic iron ore located in Western Hubei, China, exceed 2 billion tons. This is a chemical sedimentary iron ore, mainly composed of oolite (more than $60 \%$ ) $[8,9]$. Specifically, the ore comprises nuclear oolite (quartz or iron material), a collophane girdle, hematite, and a limonite girdle; the gangue is composed of fine-grained hematite and quartz feldspar; the cement comprises carbonate minerals and worm-like hematite. The concentrate consists of iron-rich oolite and some hematite, and has an iron grade of up to 55\% [10-12]. Phosphorus in the ore is mainly present in the form of collophane, where the grain sizes of the collophane girdle and monomer quartz are relatively small, as are the monomer sizes of hematite and limonite. This results in difficult separation and lower overall iron grade. It is therefore difficult to increase the iron content and decrease the phosphorus content.

Experimental research on a high-phosphorus oolitic iron ore containing $41.65 \%$ iron and $1.26 \%$ phosphorus that had been treated by suspended flash magnetic roasting, indicated that a concentrate with an iron grade above $60 \%$ could be produced by LIMS, but the phosphorus content exceeded $0.90 \%$ [13-15]. Compared with the phases present in the original ore, a significant increase in iron content was observed, but phosphorus reduction was not satisfactory. It is important to accelerate the development of high-phosphorus oolitic iron ore resources in Western Hubei, and thus this work tested the suspended flash-roasted ore using magnetic separation and reverse flotation for phosphorus reduction. The mechanism of action of a new phosphorus mineral flotation agent, toluenesulfonamide, was studied.

\section{Materials and Methods}

\subsection{Sampling}

High-phosphorus oolitic iron ore from Western Hubei that had been processed by suspended flash magnetic roasting was collected as the test sample. The sample contained $42.73 \%$ iron and $0.93 \%$ phosphorus. The main value mineral in the roasted ore was magnetite. Deleterious phosphorus mainly existed in the form of colloidal phosphate, which was characterized by its small particle size and caused great difficulty in increasing the iron content and decreasing the phosphorus content. The gangue minerals were mainly apatite, chlorite, quartz, and mica. The chemical composition is shown in Table 1. Analysis of the iron phases is shown in Table 2. X-ray diffraction phase analysis is shown in Figure 1.

Table 1. Chemical composition of oolitic iron ore sample (\%).

\begin{tabular}{ccccccccccccc}
\hline Composition & $\mathbf{F e}$ & $\mathbf{P}$ & $\mathbf{S}$ & $\mathbf{A s}$ & $\mathbf{S i O}_{2}$ & $\mathbf{C a O}$ & $\mathbf{M g O}$ & $\mathbf{A l}_{2} \mathbf{O}_{3}$ & $\mathbf{K}_{\mathbf{2}} \mathbf{O}$ & $\mathbf{N a}_{\mathbf{2}} \mathrm{O}$ & $\mathbf{T i O}_{2}$ & $\mathbf{V}_{\mathbf{2}} \mathbf{O}_{5}$ \\
\hline Content & 42.73 & 0.93 & 0.008 & 0.006 & 15.63 & 6.12 & 0.67 & 4.55 & 0.33 & 0.055 & 0.033 & 0.016 \\
\hline
\end{tabular}

Table 2. Iron phase analysis of oolitic iron ore sample (\%).

\begin{tabular}{ccccccc}
\hline Composition & TFe & Magnetite & Hematite & Pyrite & Ferrosilite & Siderite \\
\hline Content & 42.73 & 40.11 & 0.07 & 0.02 & 2.52 & 0.01 \\
Distribution & 100.00 & 93.87 & 0.16 & 0.05 & 5.89 & 0.03 \\
\hline
\end{tabular}




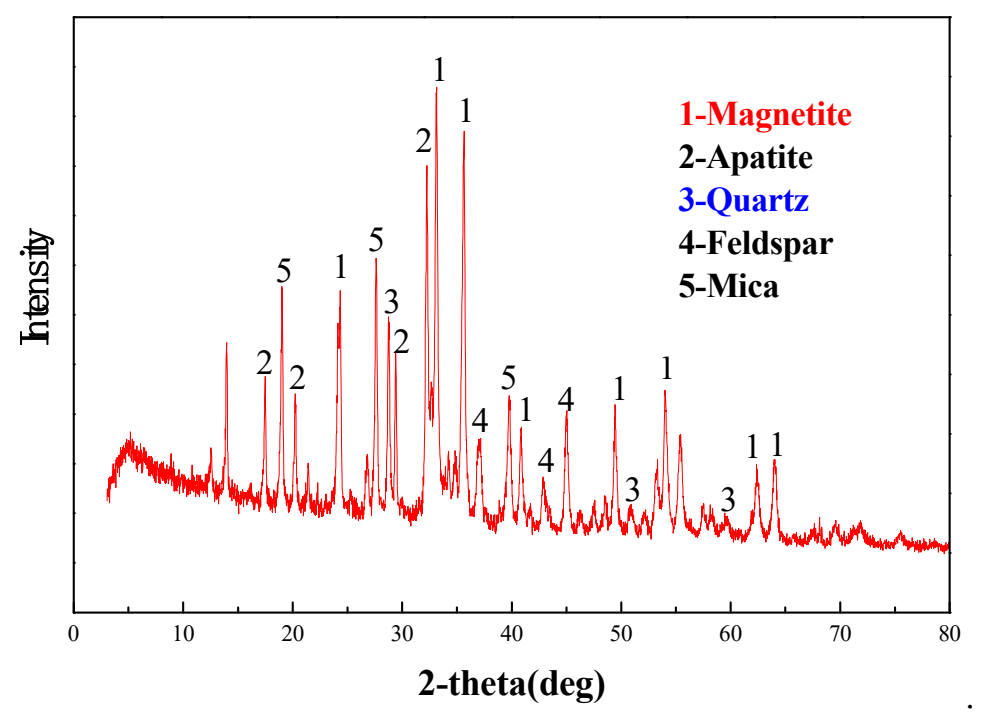

Figure 1. X-ray diffraction phase analysis of oolitic iron ore sample.

\subsection{Low-Intensity Magnetic Separation}

For each flotation test, $500 \mathrm{~g}$ samples were put into a $6.25 \mathrm{dm}^{3} \varphi 240 \times 90$ conical ball mill. The grinding density was set at 60\%. The pulp was then placed in a XCGS-13( $\varphi 50)$ Davis Magnetic Tube (Jinlin Exploration Machinery Plant, Shenyang China) with special magnetic field intensity for $10 \mathrm{~min}$ to concentrate the high-grade iron. Good separation between the magnetic and nonmagnetic material was achieved, and both the concentrate and tailings were filtered and dried for chemical analysis.

\subsection{Reverse Flotation}

Reverse flotation, aimed at reducing the phosphorus content, was carried out using an XFD-1.5L hanging tank flotation machine (Jinlin Exploration Machinery Plant, China) operating at a spindle speed of $1650 \mathrm{r} / \mathrm{min}$. A $500 \mathrm{~g}$ mass of iron concentrate was added to the $1.5 \mathrm{~L}$ flotation tank. Distilled water $(1.0 \mathrm{~L})$ was added and the pulp stirred and mixed for $3 \mathrm{~min}$, followed by adjustment to the required $\mathrm{pH}$ using sodium carbonate or sodium hydroxide. After $10 \mathrm{~min}$ of pulping, the depressant was added to the slurry and conditioned for $3 \mathrm{~min}$. Then, the collectors for dephosphorization were added and agitated for $3 \mathrm{~min}$. Before aeration, the frothers for improving the bubble were added, with another 2 min of stirring. After 3 mins of flotation, the froth (flotation tailings) and in-tank product (iron concentrate) were separately were filtered, dried at $80^{\circ} \mathrm{C}$ for $4 \mathrm{~h}$, and weighed. Quantitative analyses of iron and phosphorus were conducted to calculate the recoveries of iron and phosphorus.

\subsection{Mechanism of Reverse Flotation}

\section{(1) Zeta Potential Measurement}

The prepared magnetic iron concentrate sample of $<0.038 \mathrm{~mm}$ particle size was further ground using an agate mortar to obtain a powder of particle size $<5 \mu \mathrm{m}$ that was subjected to zeta potential measurement. In the test, $0.02 \mathrm{~g}$ of the ore sample was placed in a beaker, followed by addition of $40 \mathrm{~mL}$ of ultrapure water, adjustment of the $\mathrm{pH}$ value with $\mathrm{HCl}$ or $\mathrm{NaOH}$ solution, and addition of different collectors. Magnetic stirring was carried out for $10 \mathrm{~min}$ and the contents were then allowed to stand for $5 \mathrm{~min}$. The supernatant was transferred to a Tiselius apparatus and zeta potential measurement was performed using a JS94H microelectrophoresis apparatus. Each experimental condition was measured three times and the average values are reported. 
(2) Infrared Spectroscopy

Infrared spectra of the mineral surfaces before and after the action of different agents were determined using an IR Affinity 1 Fourier-Transform infrared spectrometer (Zhongshi Walker (Tianjin) Technology Development Co., Ltd., Shenyang, China).

An iron concentrate sample with a mass of $2 \mathrm{~g}$ and ground to a fineness of $<5 \mu \mathrm{m}$ was added into the flotation tank and stirred, followed by addition of various chemicals according to the flotation test sequence. The sample was removed on completion of pulping, vacuum-filtered, and the solid product was dried in air at room temperature. A mass of $1 \mathrm{mg}$ of the solid was mixed with $100 \mathrm{mg}$ of spectrally pure $\mathrm{KBr}$, ground with an agate mortar, and pressed into a tablet prior to analysis.

\section{Results and Discussion}

\subsection{Low-Intensity Magnetic Separation}

Application of the roasted ore to LIMS processing was intended to increase the iron content of the product, given that the main iron-containing mineral was magnetite.

\subsubsection{Effect of Grinding Fineness}

A conical ball mill was applied to grind the suspended flash-roasted ore. A mass of $100 \mathrm{~g}$ was processed using a liquid-to-solid ratio $R=2: 1$. Grinds with $95 \%$ of the material passing $0.154 \mathrm{~mm}$, $0.074 \mathrm{~mm}, 0.038 \mathrm{~mm}$, and $0.019 \mathrm{~mm}$ were prepared to carry out the separation tests at different finenesses of grind. The LIMS magnetic-field intensity $H$ was $0.08 \mathrm{~T}$. The results are shown in Figure 2.

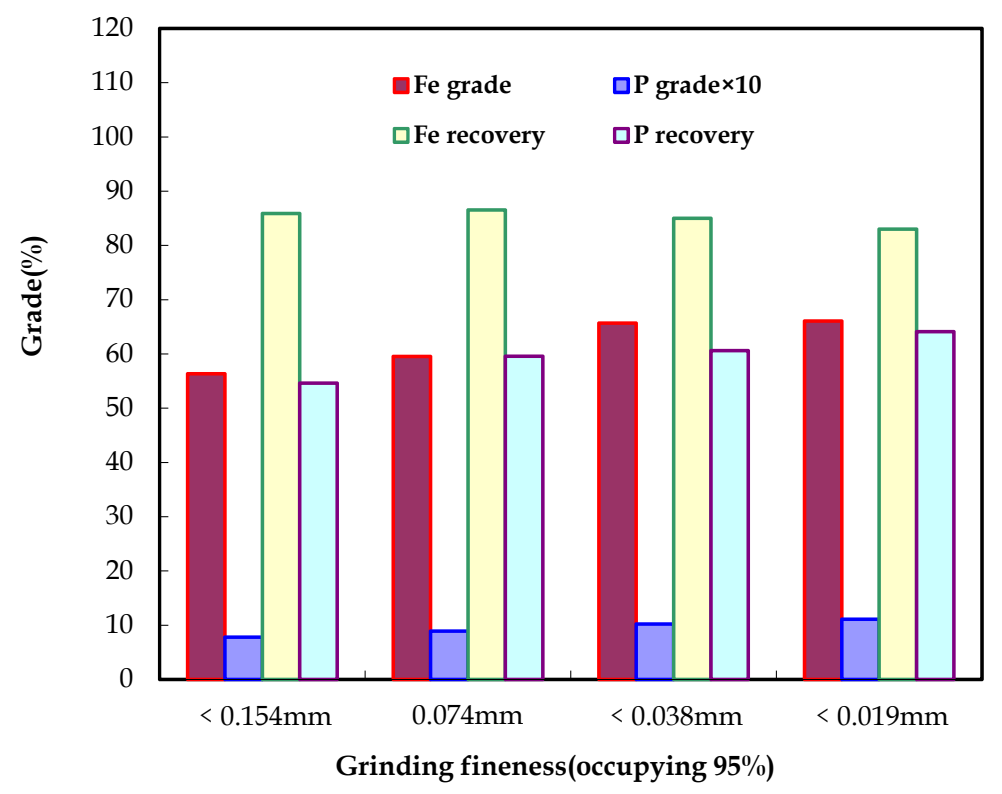

Figure 2. Effect of particles size on performance of the low-intensity magnetic separation.

Greater fineness improves the degree of liberation of minerals. Under the combined action of magnetic and mechanical forces during the magnetic separation process and at constant magnetic-field intensity, greater grinding fineness is an efficient method to improve the concentrate grade; however, finer grinding also has an adverse effect on recovery of the concentrate. A grinding fineness of $95 \%-0.038 \mathrm{~mm}$ was suitable for achieving a magnetic product with an iron content of $65.68 \%$ and phosphorus content of $0.68 \%$, at an iron recovery of $85.01 \%$. 


\subsubsection{Effect of Magnetic-Field Intensity}

A conical ball mill was applied to grind the suspended flash-roasted ore. As above, the grinding conditions employed $100 \mathrm{~g}$ ore and $R=2: 1$. A sample comprising $95 \%$ passing $-0.038 \mathrm{~mm}$ was employed to investigate the effects of different magnetic-field intensities. The results are shown in Figure 3.

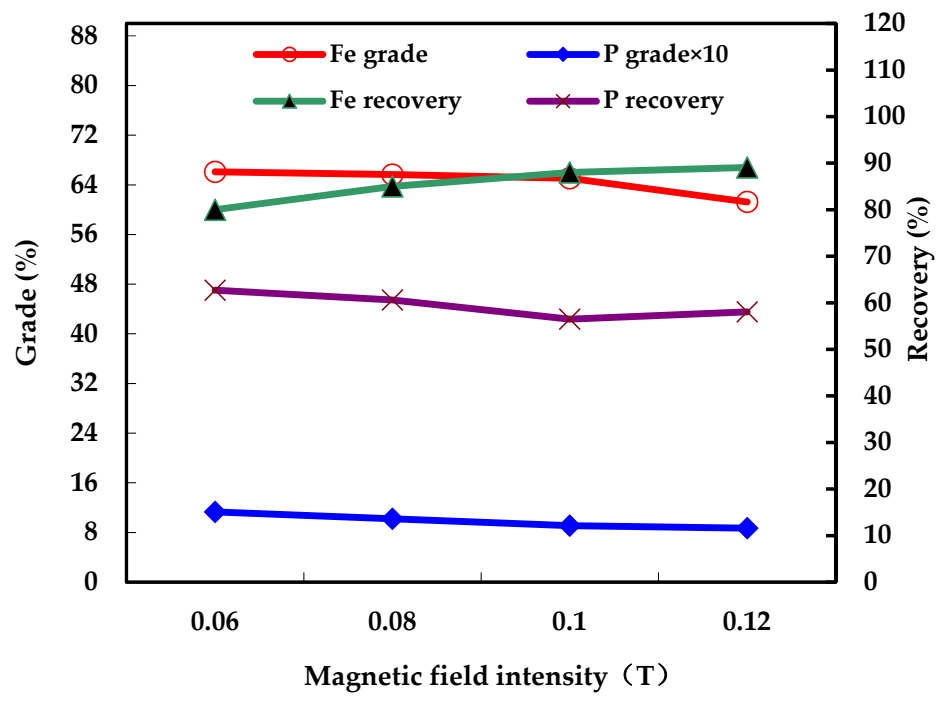

Figure 3. Effects of magnetic-field intensity on performance of the magnetic separation.

With the increase of magnetic-field intensity, the iron grade of the magnetic product steadily decreased, along with a corresponding increase of iron recovery. An initial decrease and subsequent increase of the phosphorus content with increasing magnetic-field intensity was observed. A magnetic-field intensity $H$ of $0.10 \mathrm{~T}$ was suitable to achieve the following magnetic product indexes: iron grade of $65.06 \%$, phosphorus content of $0.69 \%$, and iron recovery of $87.99 \%$.

\subsection{Reverse Flotation}

The objective of the reverse-flotation step was to selectively float phosphorus minerals from the LIMS product and thereby achieve a reduction in the phosphorus content of the iron concentrate.

\subsubsection{Effect of Collector}

Lauryl amine, sodium oleate, toluenesulfonamide(ST), and a mixed amine $\left(\mathrm{C}_{12 \sim 17}\right)$ were applied as reverse-flotation phosphorus mineral collectors on the LIMS iron concentrates. Conditions employed a $\mathrm{Na}_{2} \mathrm{CO}_{3}$-adjusted pulp pH of 8 , starch dosage of $800 \mathrm{~g} / \mathrm{t}$, collector dosage of $600 \mathrm{~g} / \mathrm{t}$, and pine alcohol oil dosage of $40 \mathrm{~g} / \mathrm{t}$. The results are shown in Figure 4.

Using lauryl amine, sodium oleate, and the mixed amine as collectors, the iron grades of the flotation tailings exceeded $60 \%$, which represented high losses of iron, and relatively high phosphorus contents of the iron concentrate were obtained $(>0.60 \%)$. In contrast, the toluenesulfonamide(ST) had an obvious effect on phosphorus reduction: the concentrate contained an iron grade of $66.57 \%$, phosphorus content of $0.36 \%$, and iron recovery was $90.01 \%$. 


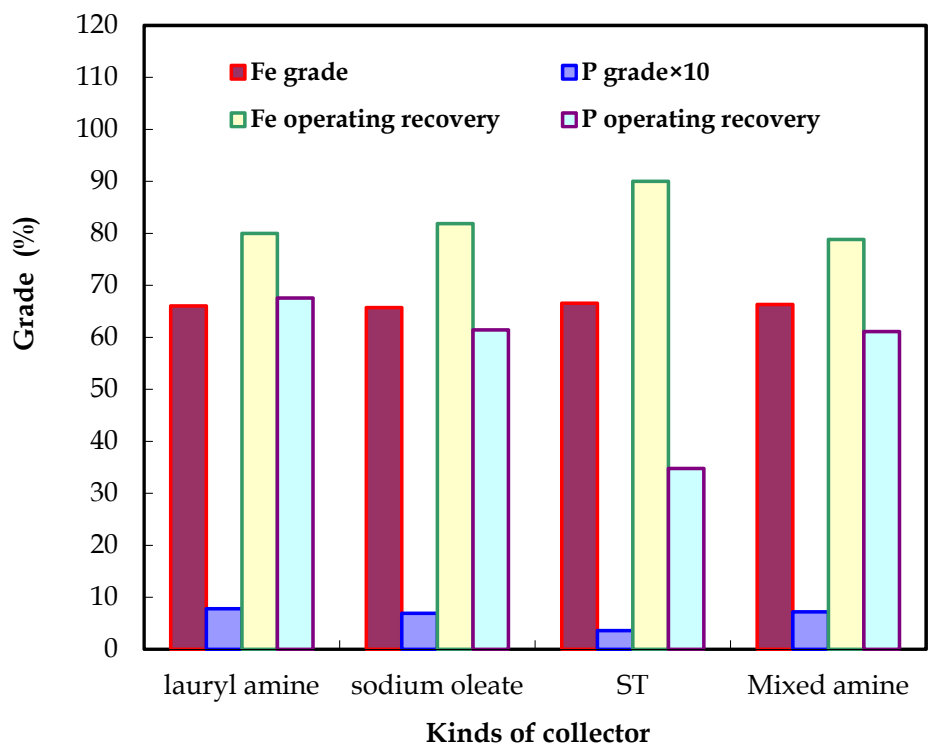

Figure 4. Effect of collector on the iron and phosphorus grades and recoveries in reverse flotation.

\subsubsection{Effect of Collector Dosage}

Increased dosage of the collector during a flotation process can improve recovery, but excessive dosage can easily target other minerals and affect the grade of the concentrate [16-19]. Appropriate collector dosage is not only beneficial to improving the flotation index, but also plays a key role in the regulation of operating costs. Tests were carried out using a $\mathrm{Na}_{2} \mathrm{CO}_{3}$-adjusted pulp $\mathrm{pH}$ of 8 , starch dosage of $800 \mathrm{~g} / \mathrm{t}$, and pine alcohol oil dosage of $40 \mathrm{~g} / \mathrm{t}$. The results are shown in Figure 5 .

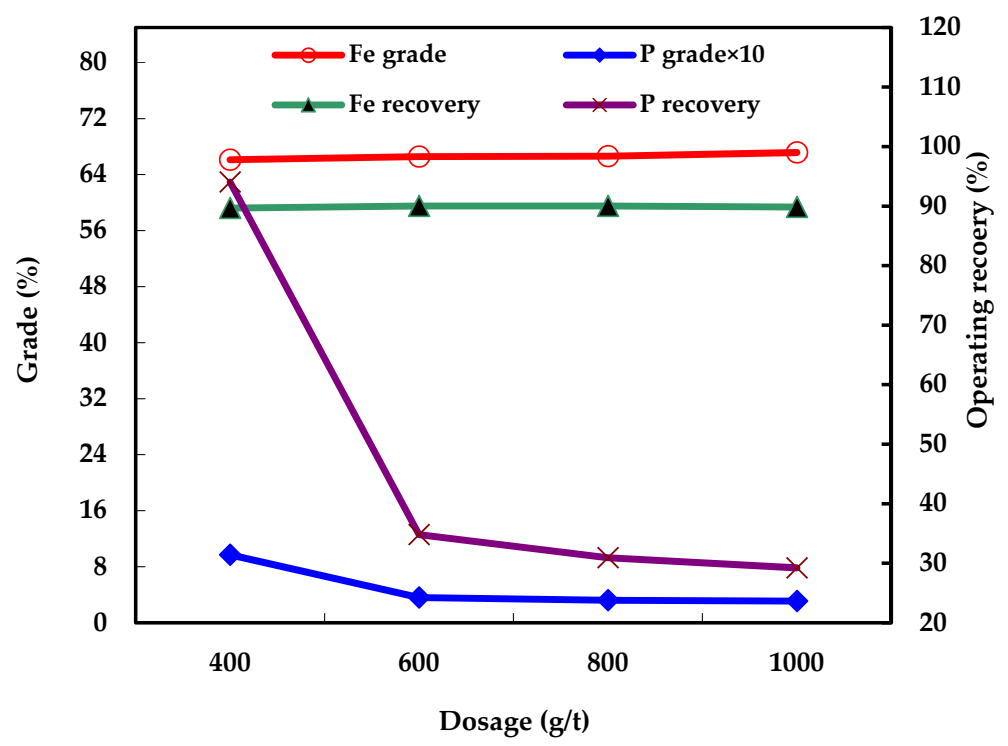

Figure 5. Effect of toluenesulfonamide dosage on iron and phosphorus grades and recoveries in reverse flotation.

With increased dosage of toluenesulfonamide, the iron grade of the concentrate steadily increased, along with an initial increase and subsequent decrease in iron recovery and a regular decrease in phosphorus content. When the collector dosage increased to $1000 \mathrm{~g} / \mathrm{t}$, the phosphorus content of the concentrate was reduced to a minimum of $0.31 \%$; at a collector dosage of $800 \mathrm{~g} / \mathrm{t}$, the phosphorus content increased by only $0.01 \%$. These results indicated that an increase in the dosage of collector was beneficial to the reduction of phosphorus content in the iron concentrate; however, excessive collector 
dosage led to an unsatisfactory effect. To improve the quality of the iron concentrate, it was necessary to set reasonable conditions by taking other factors into account; thus, an toluenesulfonamide dosage of $800 \mathrm{~g} / \mathrm{t}$ was considered ideal, yielding the following performance: iron grade of $66.63 \%$, phosphorus content of $0.32 \%$, and iron recovery of $90.02 \%$.

\subsubsection{Effect of Inhibitor Dosage}

Addition of an inhibitor in the flotation process improves the hydrophilicity of non-target minerals, weakens adsorption by the collector, and enhances the collection ability of the target mineral. On LIMS processing of the suspended flash-roasted ore, most of the gangue minerals entered the non-magnetic product. The main gangue components of the magnetic product were phosphorus-containing minerals [20-22]. It was necessary to inhibit flotation of magnetite during the process of reverse flotation and phosphorus reduction. Starch is the main inhibitor used for iron minerals. Starch is also a flocculant, and therefore either excessive or too little dosage has an important influence on magnetite inhibition [23,24]. Tests were carried out using a $\mathrm{Na}_{2} \mathrm{CO}_{3}$-adjusted pulp $\mathrm{pH}$ of 8 , toluenesulfonamide dosage of $800 \mathrm{~g} / \mathrm{t}$, and pine alcohol oil dosage of $40 \mathrm{~g} / \mathrm{t}$. The results are shown in Figure 6.

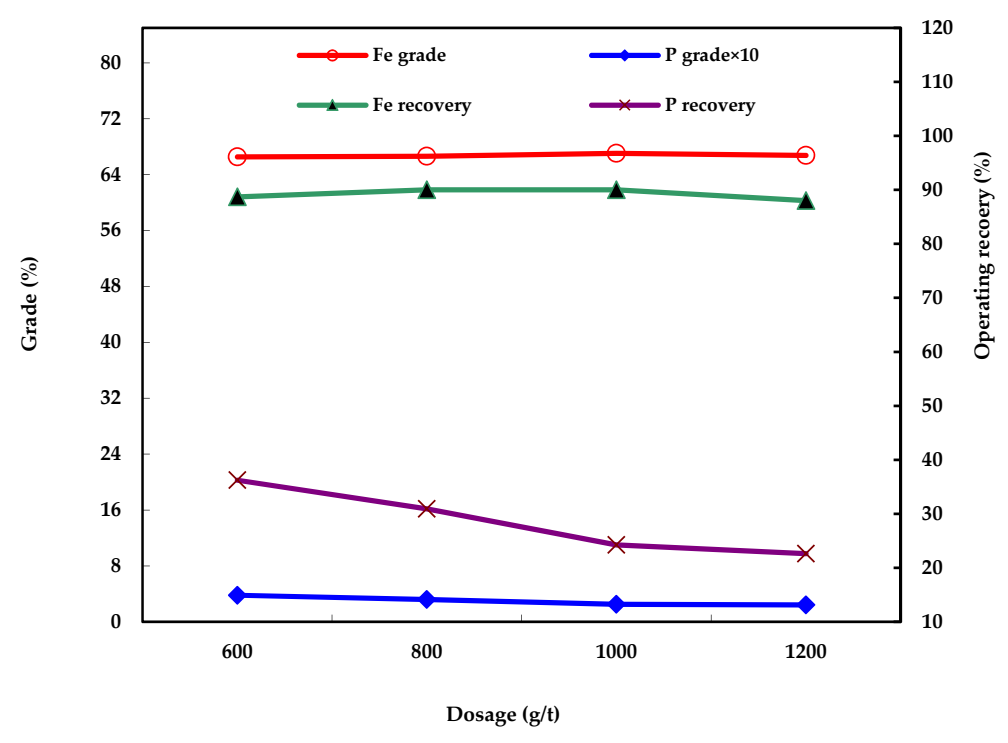

Figure 6. Effect of starch dosage on iron and phosphorus grades and recoveries in reverse flotation.

Increased dosage of starch reduced the iron content of the froth product, thereby reducing the losses of iron. When the starch dosage was increased to $1000 \mathrm{~g} / \mathrm{t}$, the iron grade of the concentrate increased to $67.05 \%$, the phosphorus content was reduced to $0.25 \%$, and the iron recovery was $90.01 \%$; at a starch dosage of $1200 \mathrm{~g} / \mathrm{t}$, the iron grade was reduced to $66.75 \%$, the phosphorus content was reduced to $0.24 \%$, and the iron recovery was $87.99 \%$. This further indicated that excessive dosage of starch caused a certain flocculation effect in addition to its inhibition of magnetite flotation; in the absence of phosphorus-containing minerals and toluenesulfonamide, this would adversely affect the quality of the iron concentrate product. A reasonable starch dosage was therefore considered to be $1000 \mathrm{~g} / \mathrm{t}$, which gave a concentrate with an iron grade of $67.05 \%$, phosphorus content of $0.25 \%$, and iron recovery of $90.01 \%$.

\subsubsection{Effect of Pulp pH}

A suitable pulp $\mathrm{pH}$ is necessary to ensure that the flotation agent is adsorbed by the target mineral. Tests were carried out using various $\mathrm{Na}_{2} \mathrm{CO}_{3}$-adjusted pulp $\mathrm{pH}$ values, toluenesulfonamide dosage 
of $800 \mathrm{~g} / \mathrm{t}$, starch dosage of $1000 \mathrm{~g} / \mathrm{t}$, and pine alcohol oil dosage of $40 \mathrm{~g} / \mathrm{t}$. The results are shown in Figure 7.

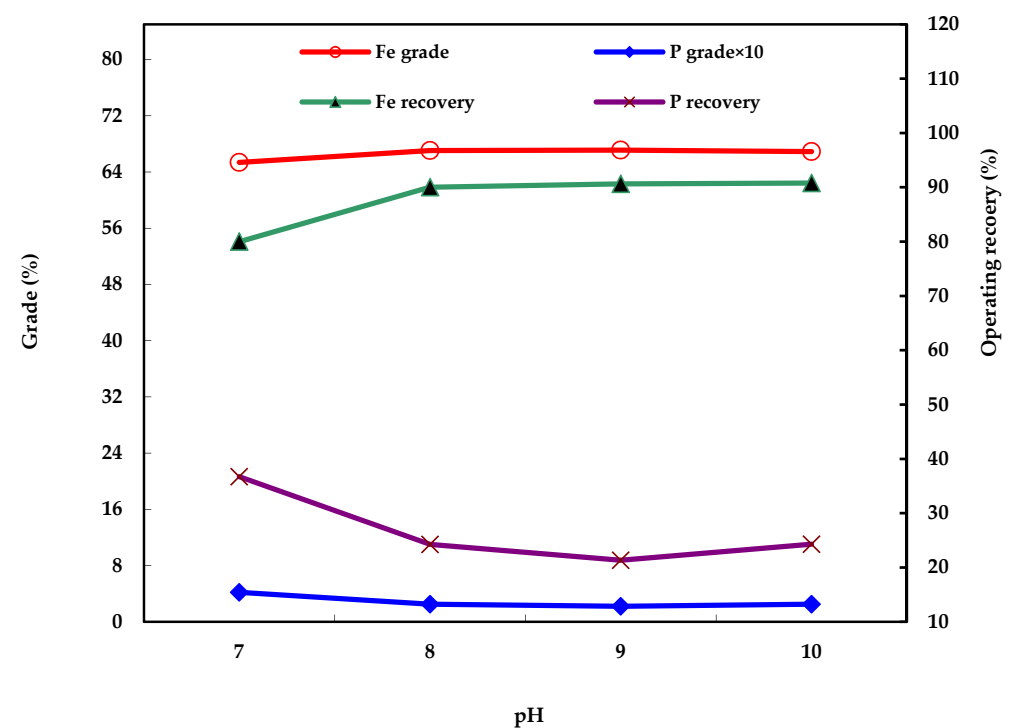

Figure 7. Effects of pulp pH value on iron and phosphorus grades and recoveries in reverse flotation.

As the $\mathrm{pH}$ of the pulp increased, the grade of the iron concentrate first increased and then decreased; the phosphorus content exhibited the opposite trend. If the $\mathrm{pH}$ is too high during a flotation process, the viscosity of the pulp increases, which prevents adhesion of minerals to the froth and thus affects the separation of phosphorus minerals and magnetite $[25,26]$. A flotation pulp $\mathrm{pH}$ value of 9 was most suitable, achieving the following performance: iron content of $67.11 \%$, phosphorus content of $0.22 \%$, and iron recovery of $90.61 \%$.

\subsubsection{Effect of Time on Reverse-Flotation Scavenging Process}

As shown above, a single-rougher reverse-flotation stage was used to process the LIMS iron concentrate and ideal phosphorus reduction was obtained. To further investigate whether it was possible to achieve deep dephosphorization by increasing the scavenging time and thereby provide better raw materials for iron concentrate products to steel smelters, the flowsheet shown in Figure 8 was used to evaluate the effect of scavenging time on decreasing the phosphorus content of the product. The results are shown in Table 3.

Use of a single rougher and single scavenger stage in reverse flotation of the LIMS concentrate reduced the content of deleterious phosphorus to less than $0.20 \%$. Therefore, based on the overall process, one rougher and one scavenger would achieve a concentrate yield of $1.48 \%+84.17 \%=85.65 \%$, with an iron grade of $(1.48 \% \times 58.89 \%+84.17 \% \times 67.68 \%) /(1.48 \%+84.17 \%)=67.53 \%$, a phosphorus content of $(1.48 \% \times 2.58 \%+84.17 \% \times 0.08 \%) /(1.48 \%+84.17 \%)=0.12 \%$, and an iron recovery of $(1.34 \%+87.56 \%)=88.90 \%$.

Table 3. Effect of scavenging time on iron and phosphorus grades and recoveries in reverse flotation (\%).

\begin{tabular}{ccccccc}
\hline \multirow{2}{*}{ Products } & \multicolumn{2}{c}{ Yield } & \multicolumn{2}{c}{ Grade } & \multicolumn{2}{c}{ Recovery } \\
\cline { 2 - 7 } & Individual & Cumulative & Fe & P & Fe & P \\
\hline Froth product I & 11.68 & 11.68 & 49.25 & 6.12 & 8.84 & 78.55 \\
Froth product II & 2.67 & 14.35 & 55.05 & 3.36 & 2.26 & 9.86 \\
Froth product III & 1.48 & 15.83 & 58.89 & 2.58 & 1.34 & 4.19 \\
Iron concentrate & 84.17 & 100.00 & 67.68 & 0.08 & 87.56 & 7.40 \\
Totals & 100.00 & & 65.06 & 0.91 & 100.00 & 100.00 \\
\hline
\end{tabular}




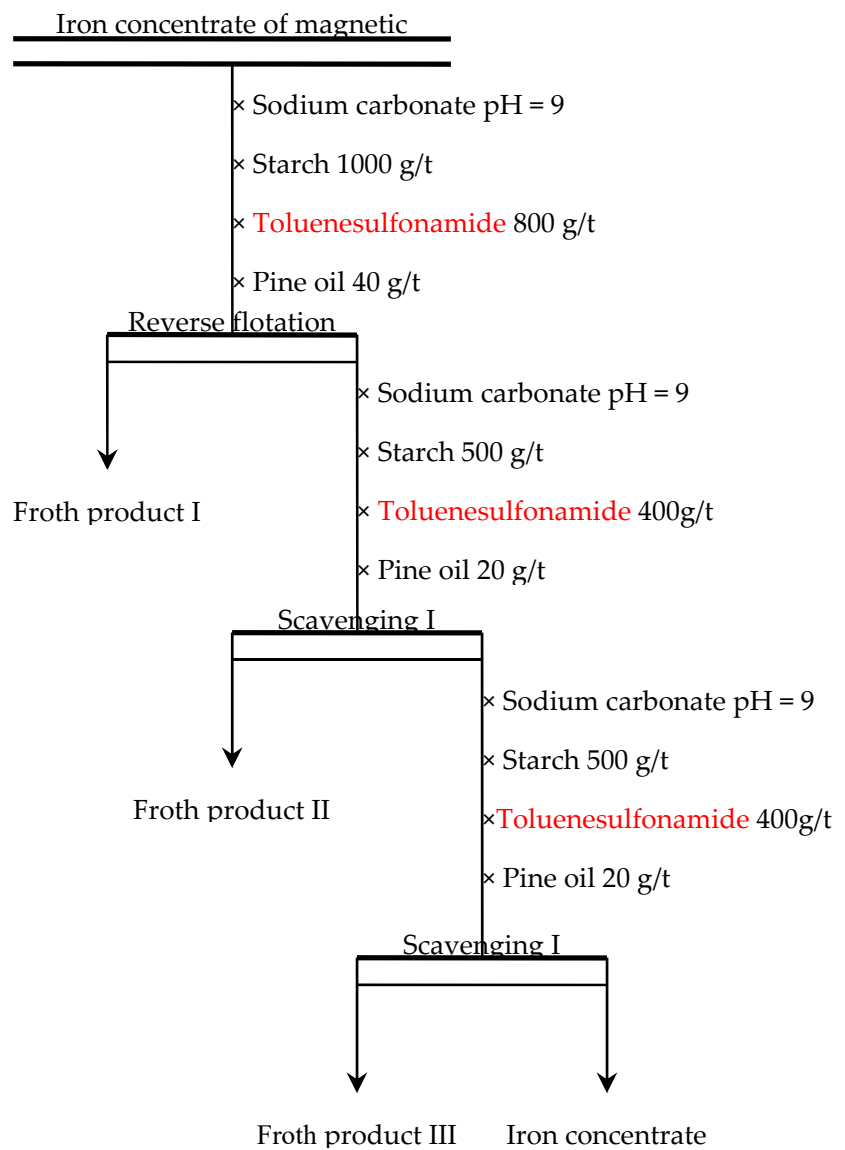

Figure 8. Flowsheet used to investigate the effect of scavenging time of reverse-flotation step.

\subsection{Combined Low-Intensity Magnetic Separation-Reverse Flotation}

The LIMS-reverse-flotation method was further used to test the effect of single-pass process conditions on increasing the iron and decreasing the phosphorus contents of suspended flash-roasted high-phosphorus oolitic iron ore from Western Hubei. The flowsheet shown in Figure 9 was employed. The results are shown in Table 4. The chemical analyses are shown in Table 5.

Tables 4 and 5 show that reverse flotation with one rougher and one scavenger gave an iron concentrate with an iron grade of $67.54 \%$, phosphorus content of $0.11 \%$, and iron recovery of $78.99 \%$. In addition, the contents of other impurity elements, such as sulfur, arsenic, and silicon, were also relatively low, meeting the requirements for a high-quality iron concentrate product.

Table 4. Test results for low-intensity magnetic separation-reverse flotation process (\%).

\begin{tabular}{cccccc}
\hline \multirow{2}{*}{ Products } & \multirow{2}{*}{ Yield } & \multicolumn{2}{c}{ Grade } & \multicolumn{2}{c}{ Recovery } \\
\cline { 3 - 6 } & & Fe & $\mathbf{P}$ & Fe & $\mathbf{P}$ \\
\hline Iron concentrate & 49.98 & 67.54 & 0.11 & 78.99 & 5.91 \\
Tailings & 50.02 & 17.94 & 1.75 & 20.01 & 94.09 \\
Totals & 100.00 & 42.73 & 0.93 & 100.00 & 100.00 \\
\hline
\end{tabular}

Table 5. Chemical analyses of iron concentrate obtained in single-pass low-intensity magnetic separation-reverse flotation process (\%).

\begin{tabular}{ccccccccc}
\hline Composition & $\mathbf{F e}$ & $\mathbf{P}$ & $\mathbf{S}$ & $\mathrm{As}$ & $\mathrm{SiO}_{2}$ & $\mathrm{CaO}$ & $\mathbf{M g O}$ & $\mathrm{Al}_{2} \mathrm{O}_{3}$ \\
\hline Content & 67.54 & 0.11 & 0.002 & 0.004 & 9.63 & 3.12 & 0.22 & 0.26 \\
\hline
\end{tabular}




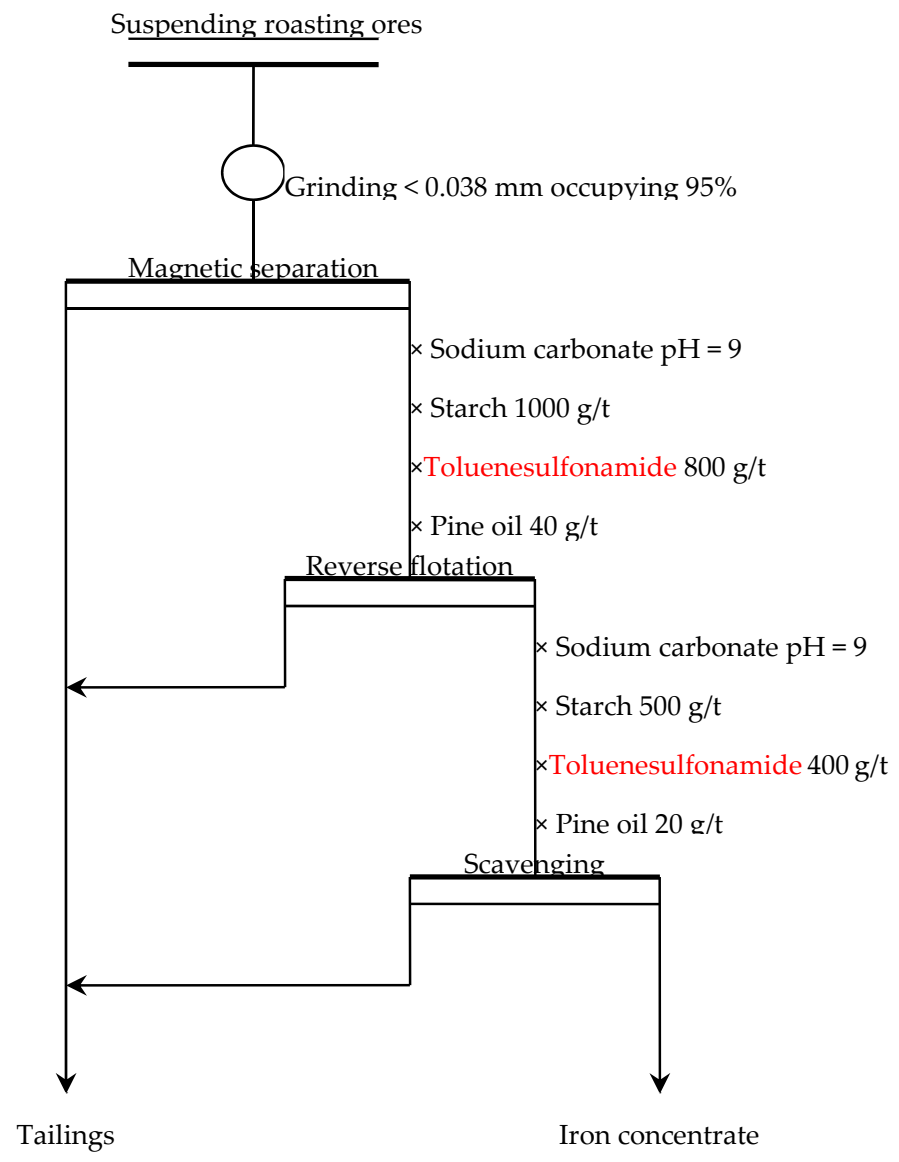

Figure 9. Combined test flowsheet for low-intensity magnetic separation-reverse flotation process.

\subsection{Mechanism of Phosphorus Reduction Using New Phosphorus Mineral Toluenesulfonamide}

\subsubsection{Electrodynamic Potential Analysis of Mineral Surfaces}

The results of electrodynamic potential measurements of apatite, magnetite, quartz, and chlorite before and after the addition of toluenesulfonamide are shown in Figure 10. The isoelectric point of apatite was 5.8; after addition of toluenesulfonamide, the isoelectric point moved to 3.6, which indicated that the collector was characteristically adsorbed on the surface of the apatite. Similarly, the isoelectric point of magnetite was 6.8 , which changed to 3.8 after addition of the collector, again indicating characteristic adsorption of toluenesulfonamide on this mineral. The isoelectric point of quartz was 3.2; after the addition of toluenesulfonamide, the electrodynamic potential became negative, indicating a significant change and thus characteristic adsorption of the collector on the quartz surface. The isoelectric point of chlorite was 5.8, which remained the same after the addition of toluenesulfonamide, indicating no characteristic adsorption. These results showed that toluenesulfonamide exhibited characteristic adsorption on the surfaces of apatite, magnetite, and quartz, but not on chlorite. 

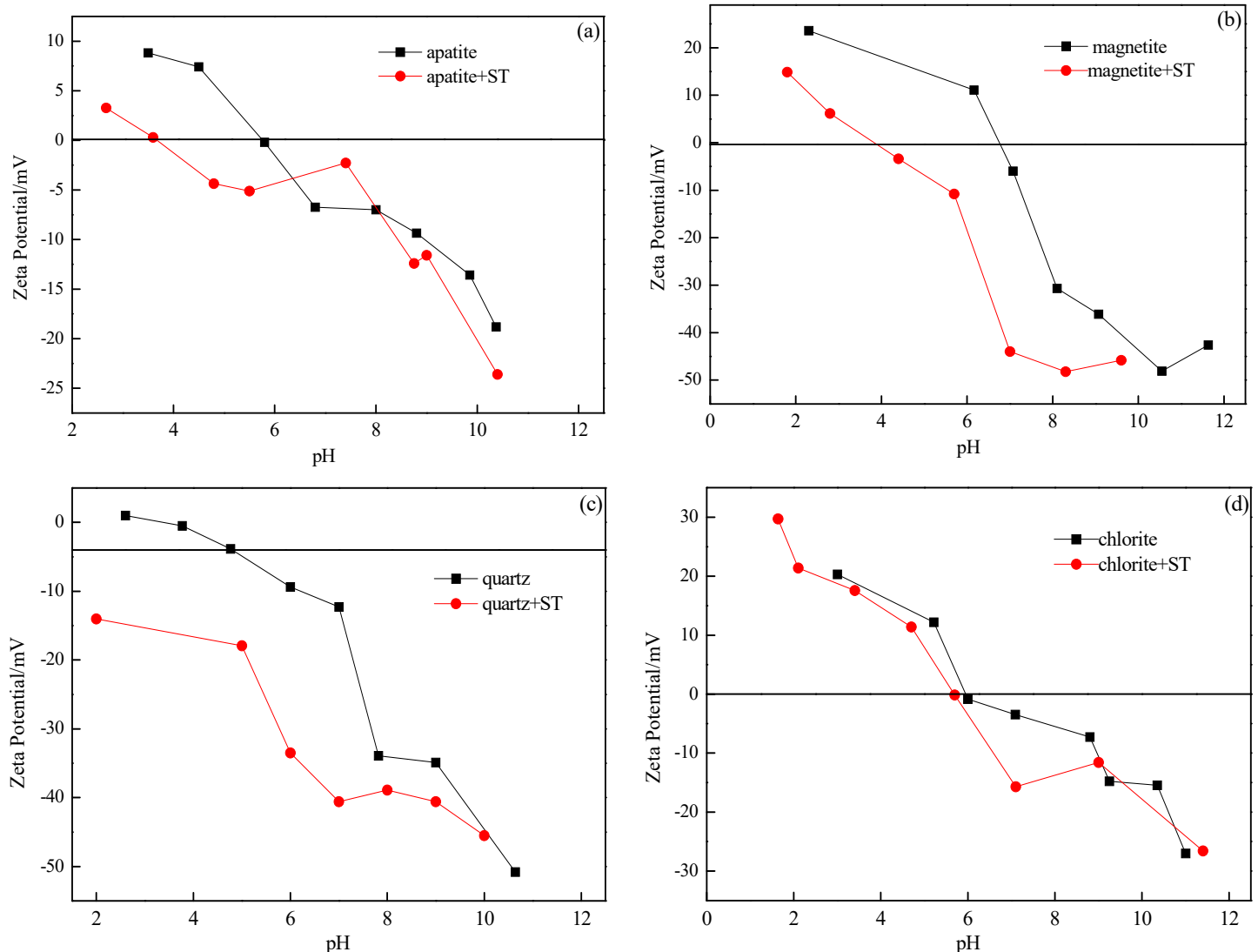

Figure 10. Electrodynamic potential analyses of (a) apatite, (b) magnetite, (c) quartz, and (d) chlorite mineral surfaces before and after the addition of toluenesulfonamide(ST).

\subsubsection{Infrared Analysis of Flotation Reagents}

\section{(1) Starch}

The infrared spectrum of starch is shown in Figure 11. The starch molecule contains a large number of $-\mathrm{OH},-\mathrm{CH}, \mathrm{C}=\mathrm{C}$, and $\mathrm{C}-\mathrm{O}-\mathrm{C}$ groups. The hydrogen bonding $-\mathrm{OH}$ stretching vibration adsorption occurred at $3419.96 \mathrm{~cm}^{-1}$; the $\mathrm{C}-\mathrm{H}$ stretching vibration ranged from $2750 \mathrm{~cm}^{-1}$ to $3300 \mathrm{~cm}^{-1}$. The $-\mathrm{CH}_{3}$ asymmetric, $-\mathrm{CH}_{2}-$ symmetric, and $-\mathrm{CH}_{2}-$ symmetric stretching adsorptions occurred at $2971.43 \mathrm{~cm}^{-1}, 2917.51 \mathrm{~cm}^{-1}$, and $2851.15 \mathrm{~cm}^{-1}$, respectively. Stretching adsorption of non-conjugated $\mathrm{C}=\mathrm{C}$ and symmetric bending adsorption of $-\mathrm{CH}_{3}$ were found at $1631.80 \mathrm{~cm}^{-1}$ and $1394.54 \mathrm{~cm}^{-1}$, respectively; stretching adsorption peaks for C-O-C were found at both $1088.48 \mathrm{~cm}^{-1}$ and $1047 \mathrm{~cm}^{-1}$; the characteristic peak at $845.96 \mathrm{~cm}^{-1}$ was assigned to the starch $\alpha$-polysaccharide 2a-type adsorption.

\section{(2) Toluenesulfonamide}

The infrared spectrum of toluenesulfonamide is shown in Figure 12. The stretching vibration of hydrogen-bonding $-\mathrm{OH},-\mathrm{CH}_{3}$ asymmetric stretching, $-\mathrm{CH}_{2}-$ symmetric stretching, and $-\mathrm{CH}_{2}-$ asymmetric stretching bands occurred at $3149.35 \mathrm{~cm}^{-1}, 2297.72 \mathrm{~cm}^{-1}, 2917.51 \mathrm{~cm}^{-1}$, and $2847.00 \mathrm{~cm}^{-1}$, respectively. The saturated fatty-acid salt was homogenized with $\mathrm{C}=\mathrm{O}$ and $\mathrm{CO}$ connected to the same carbon atom to form two $\mathrm{C}-\mathrm{O}$, where antisymmetric and symmetric stretching adsorption peaks occurred at $1557.14 \mathrm{~cm}^{-1}$ and $1465.90 \mathrm{~cm}^{-1}$, respectively. These two peaks are characteristic of fatty-acid salts. Stretching vibration adsorption peaks for C-O-C were found at $1100.92 \mathrm{~cm}^{-1}$ and $1047.00 \mathrm{~cm}^{-1}$; peaks attributed to the stretching vibration of non-conjugated $\mathrm{C}=\mathrm{C}$ and symmetric bending of $-\mathrm{CH}_{3}$ were found at $1644.24 \mathrm{~cm}^{-1}$ and $1403.69 \mathrm{~cm}^{-1}$, respectively. These results showed that $\mathrm{ST}$ is a fatty-acid collector. 


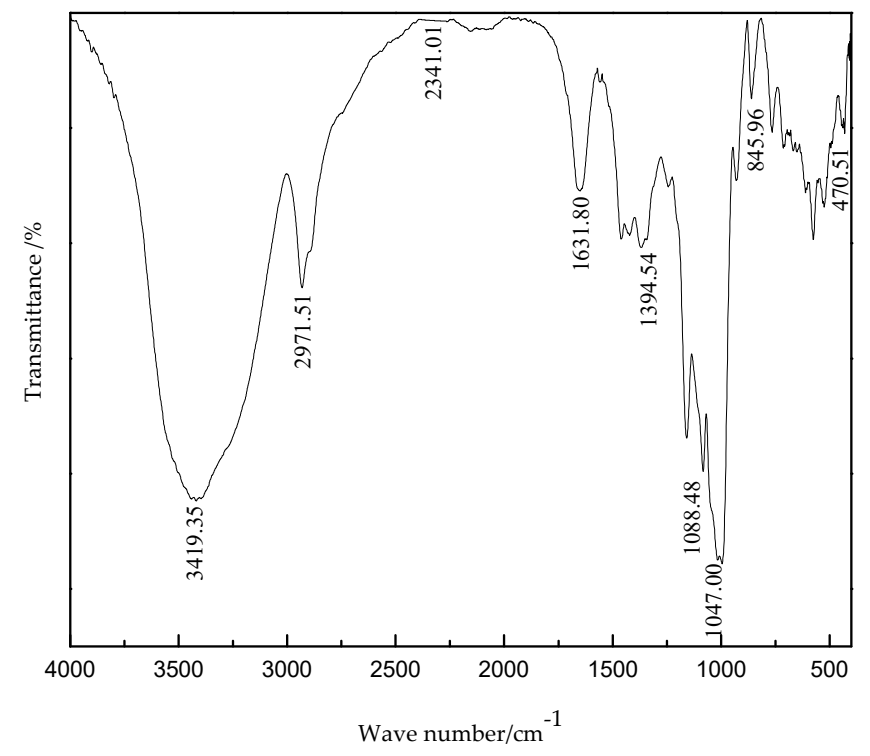

Figure 11. Infrared spectrum of starch.

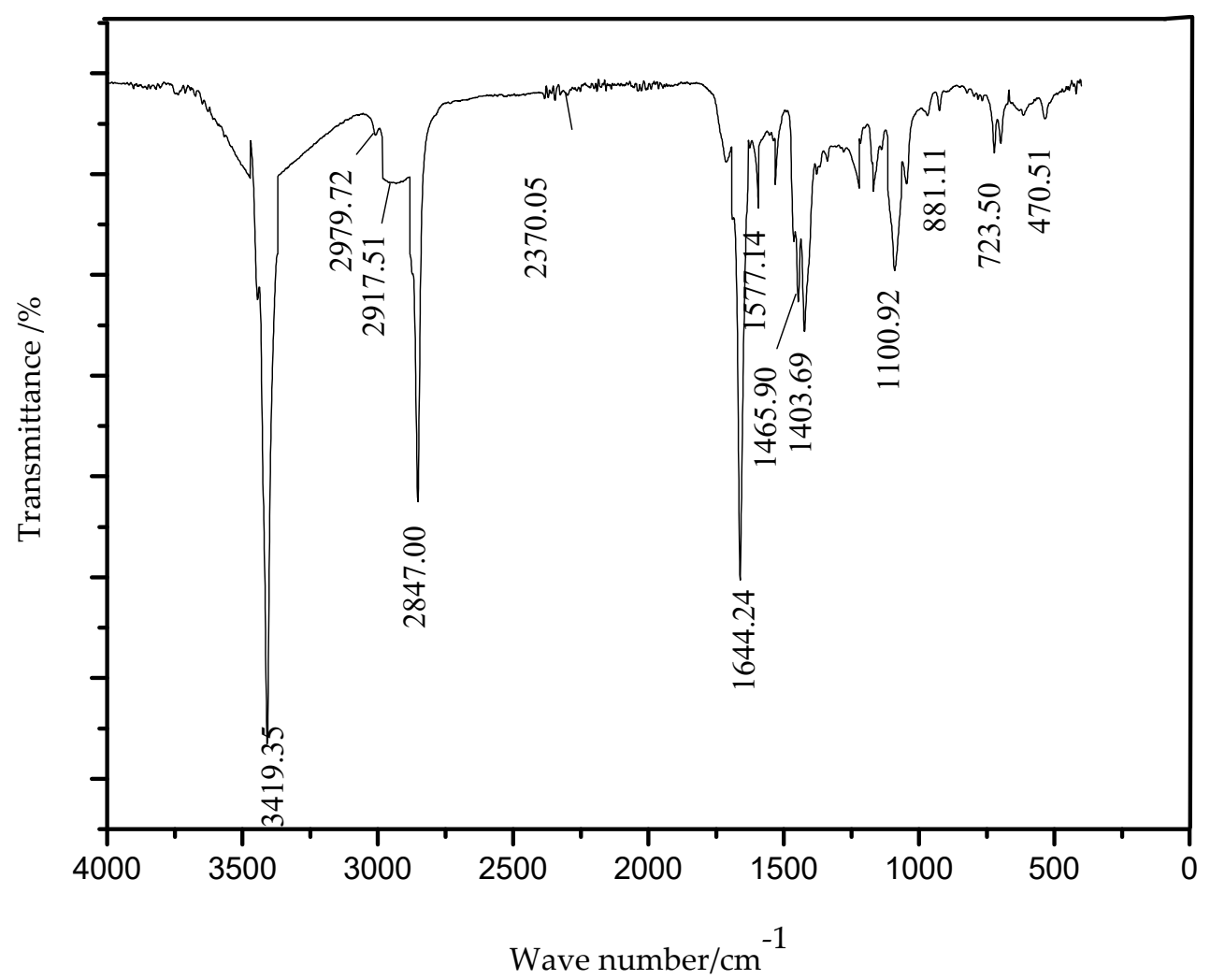

Figure 12. Infrared spectrum of toluenesulfonamide(ST).

\subsubsection{Adsorption Characteristics of Flotation Reagents on Mineral Surfaces}

\section{(1) Apatite}

The infrared spectra of apatite before and after the action of toluenesulfonamide are shown in Figure 13a and those of the combined action of starch and toluenesulfonamide are shown in Figure 13b. Figure 13a shows that significant change occurred in the infrared spectrum of apatite in the presence of toluenesulfonamide. In addition to the apatite bands, peaks due the hydrogen-bonding -OH stretching vibration at $3143.35 \mathrm{~cm}^{-1}$ and $-\mathrm{CH}_{2}-$ stretching vibrations at $2291.51 \mathrm{~cm}^{-1}$ and $2847.00 \mathrm{~cm}^{-1}$ in the ST 
spectrum also appeared at the corresponding positions, indicating adsorption of the collector on the apatite surface. In addition, a new adsorption peak appeared at $1572.50 \mathrm{~cm}^{-1}$, which was shifted by about $15.36 \mathrm{~cm}^{-1}$ compared with the characteristic peak of the hydroxyl group in the ST spectrum $\left(1557.14 \mathrm{~cm}^{-1}\right)$, indicating adsorption of toluenesulfonamide on the surface of the apatite.
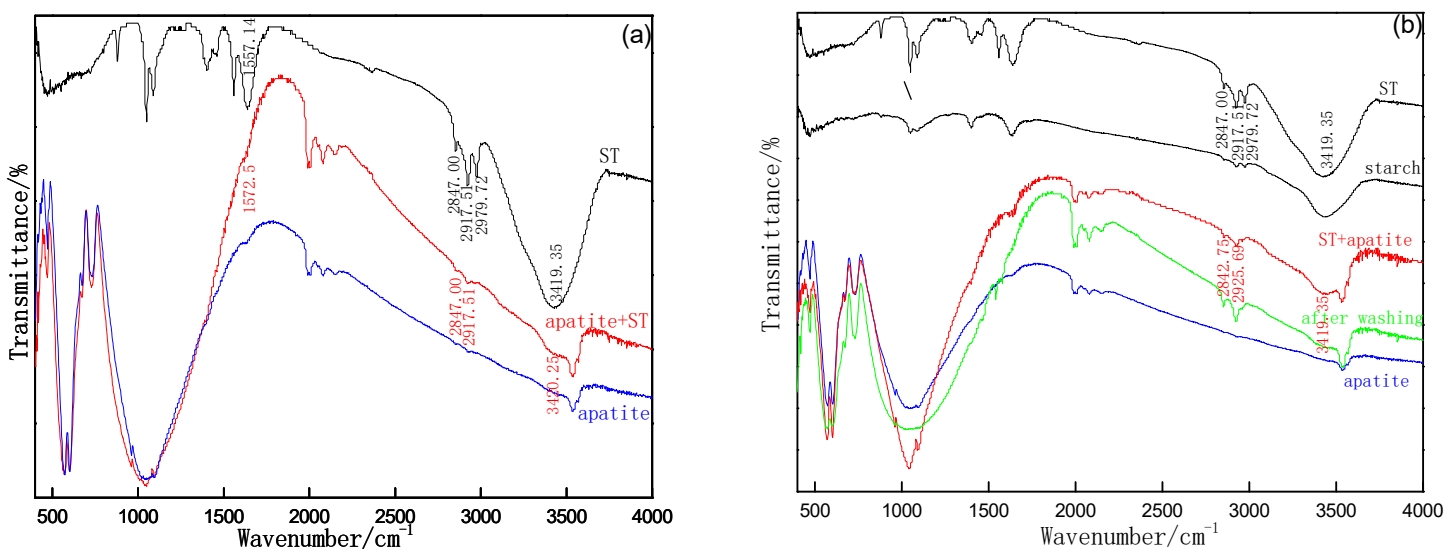

Figure 13. Infrared spectra of apatite before and after action of (a) toluenesulfonamide(ST) and (b) starch and toluenesulfonamide(ST).

The results shown in Figure 13b indicate that a significant change occurred in the infrared spectrum of apatite under the combined action of the starch inhibitor and toluenesulfonamide. In addition to the apatite adsorption peaks, the stretching vibration of the hydrogen-bonding -OH found at $3419.35 \mathrm{~cm}^{-1}$ in the ST spectrum also appeared at the corresponding position, as well as the $-\mathrm{CH}_{2}-$ stretching adsorptions at $925.69 \mathrm{~cm}^{-1}$ and $2842.75 \mathrm{~cm}^{-1}$, which shifted by $8.18 \mathrm{~cm}^{-1}$ and $4.25 \mathrm{~cm}^{-1}$, respectively. These results indicated that adsorption occurred on the apatite surface. The methylene adsorption peak on the surface of the apatite was higher after water washing, indicating that chemical adsorption of the collector molecules also occurred on the surface of apatite after the action of starch, in addition to its physical adsorption. The above analysis indicated that the toluenesulfonamide is an effective collector for apatite and that starch can enhance the collection performance: apatite was enriched in the phosphorus tailings product, which was dephosphorized with anions. These results are in good agreement with the flotation results discussed earlier.

\section{(2) Magnetite}

The infrared spectra of magnetite before and after the action of toluenesulfonamide are shown in Figure 14a; those before and after the combined action of starch and toluenesulfonamide are shown in Figure 14b. Figure 14a indicates that significant change of the infrared spectrum of magnetite occurred in the presence of toluenesulfonamide: in addition to its own bands, the stretching adsorption of the hydrogen-bonding -OH found at $3419.35 \mathrm{~cm}^{-1}$ in the ST spectrum and the symmetric stretching adsorption of $-\mathrm{CH}_{2}-$ at $2847.00 \mathrm{~cm}^{-1}$ appeared at the corresponding positions. The methylene adsorption peak appeared at $2925.95 \mathrm{~cm}^{-1}$, shifted by $8.44 \mathrm{~cm}^{-1}$ compared with the spectrum of ST alone, indicating adsorption of the collector on the magnetite surface.

Figure $14 \mathrm{~b}$ shows that changes occurred in the magnetite spectrum on the addition of starch and toluenesulfonamide. In addition to the adsorption peaks of magnetite itself, a relatively weak methylene adsorption peak was found at $2921.66 \mathrm{~cm}^{-1}$, indicating that the toluenesulfonamide adsorbed on the magnetite surface, but the effect was relatively weak. After the magnetite treated with both starch and collector was water-washed, only the characteristic peak of magnetite itself appeared: there were no adsorption peaks of the toluenesulfonamide. This indicated that the toluenesulfonamide only exhibited weak physical adsorption on the surface of magnetite in the presence of starch. Therefore, starch effectively inhibited the interaction between magnetite and the collector, causing magnetite to 
report with the floating phosphorite ore and separating it from the apatite. This finding is consistent with the results of the anion dephosphorization flotation tests.
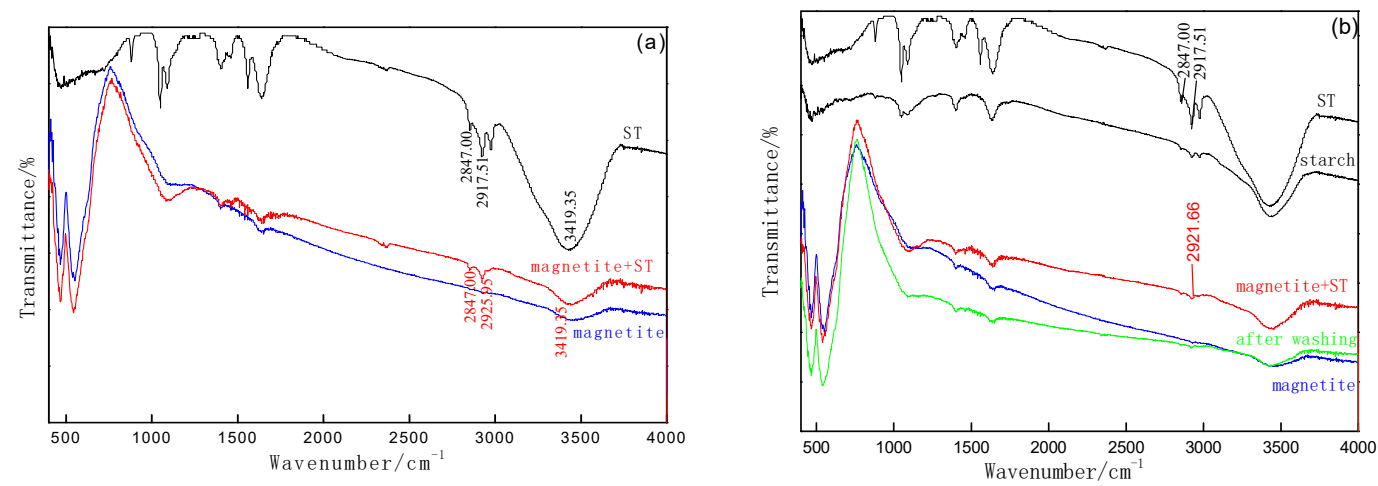

Figure 14. Infrared spectra of magnetite before and after the action of (a) toluenesulfonamide(ST). and (b) starch and toluenesulfonamide(ST).

\section{(3) Quartz}

The analogous spectra of quartz before and after the action of toluenesulfonamide and the toluenesulfonamide in the presence of starch are shown in Figure 15a,b respectively. The results shown in Figure 15a indicate that the infrared spectrum of quartz changed to some extent in the presence of the collector: in addition to its own bands, the symmetric stretching vibration attributed to $-\mathrm{CH}_{2}-$ at $2291.51 \mathrm{~cm}^{-1}$ in the toluenesulfonamide spectrum appeared at the corresponding position and methylene adsorption peaks appeared at $2794.46 \mathrm{~cm}^{-1}$ and $2838.60 \mathrm{~cm}^{-1}$, shifted by $4.08 \mathrm{~cm}^{-1}$ and $8.40 \mathrm{~cm}^{-1}$, respectively, indicating adsorption of toluenesulfonamide on the surface of the quartz. The results shown in Figure $15 \mathrm{~b}$ indicate that when the starch was added, in addition to the adsorption peaks of quartz itself, new adsorption peaks were observed at $2925.69 \mathrm{~cm}^{-1}$ and $2842.75 \mathrm{~cm}^{-1}$, which were shifted by $8.18 \mathrm{~cm}^{-1}$ and $4.25 \mathrm{~cm}^{-1}$, respectively, in comparison with the infrared spectrum of toluenesulfonamide. This indicated that the collector adsorbed on the surface of the quartz under the action of starch and collector. After water-washing of the quartz with starch and collector ST, the symmetric stretching adsorption peak of $-\mathrm{CH}_{2}-$ at $2917.51 \mathrm{~cm}^{-1}$ appeared in the ST spectrum at the corresponding position, but its intensity was weak. This indicated that the toluenesulfonamide could adsorb on the quartz surface after the addition of starch, but the addition of starch obviously weakened this adsorption. These results further indicated that the presence of a starch inhibitor weakened adsorption of toluenesulfonamide on quartz. Therefore, in the anion dephosphorization flotation process, a portion of quartz would enter the phosphorus tailings with the flotation froth under the action of toluenesulfonamide. These results were in good agreement with the relatively high silicon content in the phosphorus tailings indicated by the dephosphorization flotation tests.

\section{(4) Iron Chlorite}

The analogous infrared spectra of chlorite before and after the action of collector ST alone and in combination with starch are shown in Figure 16a,b respectively. Figure 16a shows that the infrared spectra of chlorite were almost coincident before and after the action of toluenesulfonamide, which indicated that adsorption of the collector on the chlorite surface was relatively weak. After the action of starch with the toluenesulfonamide Figure 16b, the infrared spectra of chlorite were again substantially coincident before and after the action of the flotation agents, indicating weak adsorption of both starch and toluenesulfonamide on the chlorite surface. After the chlorite treated with starch and toluenesulfonamide was water-washed, weakening intensity of the fingerprint peaks was observed. These results showed that adsorption between starch and toluenesulfonamide and chlorite was weak: chlorite therefore mainly deported with magnetite during reverse-flotation dephosphorization. 

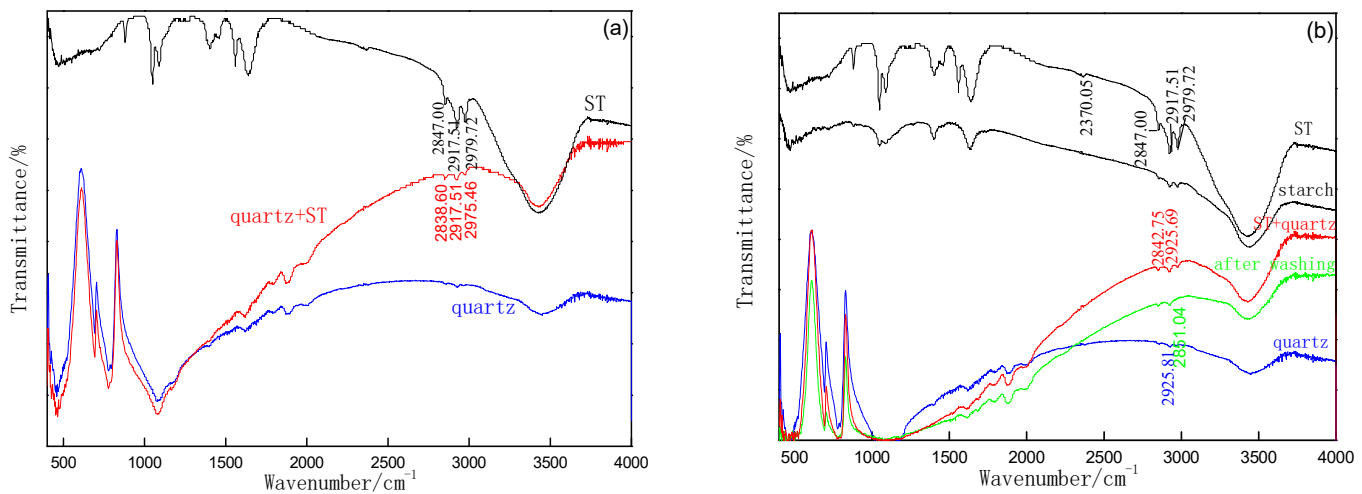

Figure 15. Infrared spectra of quartz before and after the action of (a) toluenesulfonamide(ST) and (b) starch and toluenesulfonamide(ST).
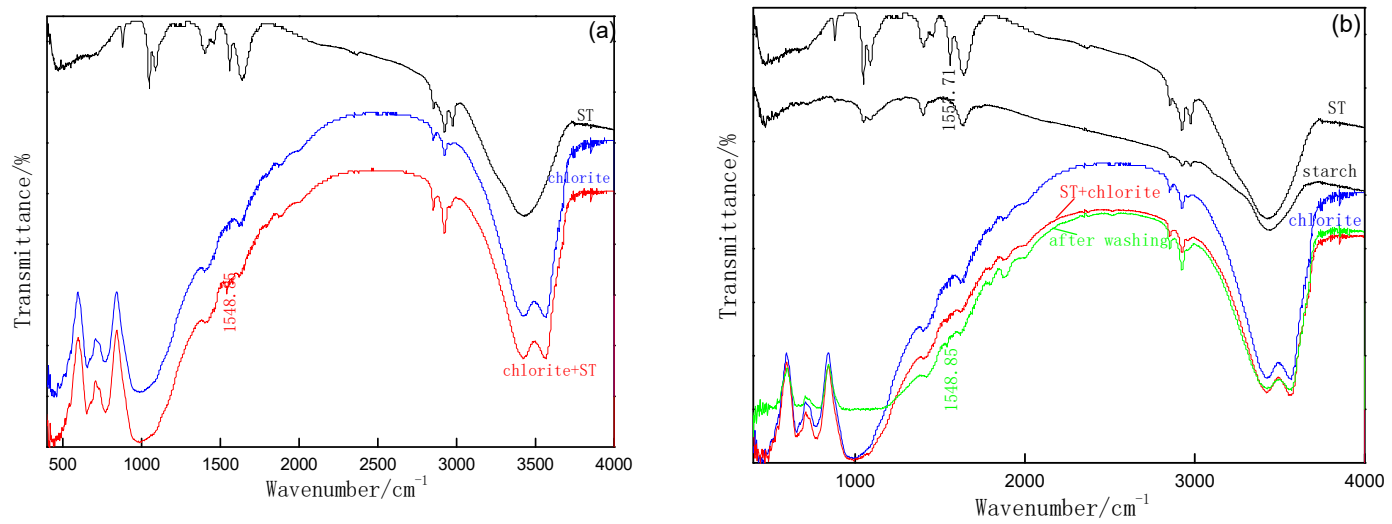

Figure 16. Infrared spectra of chlorite before and after the action (a) toluenesulfonamide(ST) and (b) starch and toluenesulfonamide(ST).

\section{Conclusions}

(1) High-phosphorus oolitic iron ore from Western Hubei that was treated by suspended flash magnetic roasting contained $42.73 \%$ iron and $0.93 \%$ phosphorus. The main valuable element was iron, present as magnetite; deleterious phosphorus existed in the roasted ore in the form of francolite (collophane); the gangue minerals were mainly apatite, chlorite, quartz, and mica.

(2) The suspended flash magnetic-roasted high-phosphorus oolitic iron ore was processed by LIMS followed by reverse flotation. Toluenesulfonamide flotation reagent was added as a high-efficiency collector for reverse flotation of the phosphorus minerals. Significant iron increase and phosphorus reduction in the concentrate grades were obtained from this combined process. Reverse flotation using a single rougher and single scavenger stage yielded the following of iron ore concentrate indexes: iron grade of $67.54 \%$, phosphorus content of $0.11 \%$, and iron recovery of $78.99 \%$. In addition, the contents of other impurity elements in the concentrate, such as sulfur, arsenic, and silicon, were also relatively low, meeting the requirements for a high-quality iron concentrate product.

(3) Study of the mechanism of phosphorus flotation by toluenesulfonamide indicated characteristic adsorption peaks of the collector on the surfaces of apatite, magnetite, and quartz, but not on chlorite. Infrared analyses indicated that toluenesulfonamide could adsorb on the surface of quartz after the addition of starch, but the adsorption was obviously weakened, indicating that the presence of starch inhibitor weakened the adsorption between toluenesulfonamide and quartz. Adsorption of starch and toluenesulfonamide on the surface of chlorite was weak.

Author Contributions: This is a joint work of the two authors; each author was in charge of their expertise and capability: J.X. or conceptualization, methodology, validation, original draft preparation, and writing, L.Z. for formal analysis and investigation. 
Funding: This work was supported by the Sichuan Science and Technology Program (Grant Nos. 2018FZ0092, 2019YFS0451, and 2019YFS0452); Open Foundation of the State Key Laboratory of Refractories and Metallurgy, Wuhan University of Science and Technology (Grant No. ZR201801); Open Foundation of the Key Laboratory of Radioactive and Rare and Sparse Minerals of the Ministry of Land and Resources (Grant No. RRSM-KF2018-02).

Acknowledgments: We thank Kathryn Sole and Gabrielle David from Liwen Bianji, Edanz Group China (www.liwenbianji.cn/ac), for editing the English text of drafts of this manuscript.

Conflicts of Interest: The authors declare no conflict of interest. The funders had no role in the design, analyses, and interpretation of any data of the study.

\section{References}

1. Guo, L.; Gao, J.T.; Zhong, S.P.; Guo, Z.C. Phosphorus migration mechanism between iron and highphosphorus gangue phase at high temperatures. J. Iron Steel Res. Int. 2019, 26, 113-122. [CrossRef]

2. Cai, X.Y.; Qian, G.M.; Zhang, B.; Chen, Q.S.; Hu, C.Q. Selective Liberation of High-Phosphorous Oolitic Hematite Assisted by Microwave Processing and Acid Leaching. Minerals 2018, 8, 245. [CrossRef]

3. Huang, D.B.; Zong, Y.B.; Wei, R.F.; Gao, W.; Liu, X.M. Direct Reduction of High-phosphorus Oolitic Hematite Ore Based on Biomass Pyrolysis. J. Iron Steel Res. Int. 2016, 23, 874-883. [CrossRef]

4. Zhao, J.; Chen, Z.J.; Zuo, H.B.; Wang, J.S.; Xue, Q.G. Research on Reaction Mechanism of Vacuum Carbon Thermal Reduction and Dephosphorization in High Phosphate Iron Ore. Metals 2018, 8, 3. [CrossRef]

5. Zhang, H.Q.; Zhang, Z.Q.; Luo, L.Q.; Yu, H. Behavior of Fe and P during reduction magnetic roasting-separation of phosphorus-rich oolitic hematite. Energy Sources Part A Recovery Util. Environ. Eff. 2019, 41, 47-64. [CrossRef]

6. Zhao, Y.L.; Chen, L.C.; Yi, H.; Zhang, Y.M.; Song, S.X.; Bao, S.X. Vanadium Transitions during Roasting-Leaching Process of Vanadium Extraction from Stone Coal. Minerals 2018, 8, 63. [CrossRef]

7. Cao, Y.Y.; Zhang, Y.R.; Sun, T.C. Dephosphorization Behavior of High-Phosphorus Oolitic Hematite-Solid Waste Containing Carbon Briquettes during the Process of Direct Reduction-Magnetic Separation. Metals 2018, 8, 897. [CrossRef]

8. Quast, K. A review on the characterisation and processing of oolitic iron ores. Miner. Eng. 2018, 126, 89-100. [CrossRef]

9. Zhang, Y.Y.; Xue, Q.G.; Wang, G.; Wang, J.S. Phosphorus-Containing Mineral Evolution and Thermodynamics of Phosphorus Vaporization during Carbothermal Reduction of High-Phosphorus Iron Ore. Metals 2018, 8 , 451. [CrossRef]

10. Sun, Y.S.; Zhang, Q.; Han, Y.X.; Gao, P.; Li, G.F. Comprehensive Utilization of Iron and Phosphorus from High-Phosphorus Refractory Iron Ore. JOM 2018, 70, 144-149. [CrossRef]

11. Zhang, Y.Y.; Xue, Q.G.; Wang, G.; Wang, J.S. Gasification and Migration of Phosphorus from High-phosphorus Iron Ore during Carbothermal Reduction. ISIJ Int. 2018, 58, 2219-2227. [CrossRef]

12. Zhang, Y.Y.; Xue, Q.G.; Zuo, H.B.; Cheng, C.; Wang, G.; Han, F.; Wang, J.S. Intermittent Microscopic Observation of Structure Change and Mineral Reactions of High Phosphorus Oolitic Hematite in Carbothermic Reduction. ISIJ Int. 2017, 57, 1149-1155. [CrossRef]

13. Luo, L.Q.; Zhang, H.Q. Process mineralogy and characteristic associations of iron and phosphorus-based minerals on oolitic hematite. J. Cent. South Univ. 2017, 24, 1959-1967. [CrossRef]

14. Yang, C.C.; Zhu, D.Q.; Pan, J.; Lu, L.M. Simultaneous Recovery of Iron and Phosphorus from a High-Phosphorus Oolitic Iron Ore to Prepare Fe-P Alloy for High-Phosphorus Steel Production. JOM 2017, 69, 1663-1668. [CrossRef]

15. Wang, H.H.; Li, G.Q.; Yang, J.; Ma, J.H.; Khan, B.S. The Behavior of Phosphorus During Reduction and Carburization of High-Phosphorus Oolitic Hematite with $\mathrm{H}_{2}$ and $\mathrm{CH}_{4}$. Metall. Mater. Trans. B Process Metall. Mater. Process. Sci. 2016, 47, 2571-2581. [CrossRef]

16. Lv, C.; Wen, S.M.; Yang, K.; Bai, S.J. Beneficiation of High-Phosphorus Siderite Ore by Acid Leaching and Alkaline Oxide Reinforced Carbothermic Reduction-Magnetic Separation Process. Steel Res. Int. 2017, 88. [CrossRef]

17. Cao, Y.Y.; Sun, T.C.; Kou, J.; Xu, C.Y.; Gao, E.X. Effect of $\mathrm{Na}_{2} \mathrm{CO}_{3}$ and $\mathrm{CaCO}_{3}$ on Coreduction Roasting of Blast Furnace Dust and High-phosphorus Oolitic hematite. J. Wuhan Univ. Technol. Mater. Sci. Ed. 2017, 32, 517-524. [CrossRef] 
18. Tang, H.; Fu, X.; Qin, Y.; Qi, T. Iron recovery and phosphorus removal from oolitic high-phosphorus haematite using the FASTMELT (R) process: A comparative study of two reductants. J. South. Afr. Inst. Min. Metall. 2017, 117, 387-395. [CrossRef]

19. Zhao, D.; Li, G.Q.; Wang, H.H.; Ma, J.H. Slag/Metal Separation from $\mathrm{H}_{2}$-Reduced High Phosphorus Oolitic Hematite. ISIJ Int. 2017, 57, 2131-2140. [CrossRef]

20. Han, Y.X.; Li, G.F.; Gao, P.; Sun, Y.S. Reduction behaviour of apatite in oolitic haematite ore using coal as a reductant. Ironmak. Steelmak. 2017, 44, 287-293. [CrossRef]

21. Du, C.M.; Gao, X.; Ueda, S.; Kitamura, S.Y. Effects of Cooling Rate and Acid on Extracting Soluble Phosphorus from Slag with High P2O5 Content by Selective Leaching. ISIJ Int. 2017, 57, 487-496. [CrossRef]

22. Yu, W.; Tang, Q.Y.; Chen, J.A.; Sun, T.C. Thermodynamic analysis of the carbothermic reduction of a high-phosphorus oolitic iron ore by FactSage. Int. J. Miner. Metall. Mater. 2016, 23, 1126-1132. [CrossRef]

23. Zhu, D.Q.; Wang, H.; Pan, J.; Yang, C.C. Influence of Mechanical Activation on Acid Leaching Dephosphorization of High-phosphorus Iron Ore Concentrates. J. Iron Steel Res. Int. 2016, 23, 661-668. [CrossRef]

24. Wang, H.H.; Li, G.Q.; Zhao, D.; Ma, J.H.; Yang, J. Dephosphorization of high phosphorus oolitic hematite by acid leaching and the leaching kinetics. Hydrometallurgy 2017, 171, 61-68. [CrossRef]

25. Liu, Y.Q.; Zhang, H.; Li, Z.G.; Zhang, A.M.; Zhang, X.H.; Qing, S. Impact of slag composition activity on the behavior of phosphorus in the smelting reduction process of high-phosphorus iron ores. Int. J. Hydrogen Energy 2017, 42, 24487-24494. [CrossRef]

26. Zhao, Y.Q.; Sun, T.C.; Zhao, H.Y.; Li, X.H.; Wang, X.P. Effects of $\mathrm{CaCO}_{3}$ as Additive on Coal-based Reduction of High-phosphorus Oolitic Hematite Ore. ISIJ Int. 2018, 58, 1768-1774. [CrossRef]

(C) 2019 by the authors. Licensee MDPI, Basel, Switzerland. This article is an open access article distributed under the terms and conditions of the Creative Commons Attribution (CC BY) license (http://creativecommons.org/licenses/by/4.0/). 